\title{
Elevated cyclin E level in human clear cell renal cell carcinoma: possible causes and consequences
}

\author{
Alicja Nauman ${ }^{1 凶}$, Olga Turowska ${ }^{1}$, Piotr Poplawski ${ }^{1}$, Adam Master ${ }^{1}$, \\ Zbigniew Tanski², and Monika Puzianowska-Kuznicka ${ }^{1,3}$ \\ ${ }^{1}$ Department of Biochemistry and Molecular Biology, Medical Center of Postgraduate Education, Warszawa, \\ Poland; ${ }^{2}$ Department of Urology, Specialistic Hospital, Ostroleka, Poland; ${ }^{3}$ Department of Endocrinology, Medi- \\ cal Research Center, Polish Academy of Sciences, Warszawa, Poland
}

Received: 08 May, 2007; revised: 11 July, 2007; accepted: 31 July, 2007

available on-line: 28 August, 2007

\begin{abstract}
The expression of cyclin $\mathrm{E}$ gene $(C C N E)$ in relation to the expression of its major regulatory protein, E2F1, was examined in clear cell renal cell carcinomas (ccRCC). We show that the overexpression of E2F1 is accompanied by the significant increase of the mean amounts of cyclin $\mathrm{E}$ mRNA, as well as of total cyclin E protein and its low molecular weight forms in cancer tissues as compared to peritumoral controls. A significant increase of the mean amount of total cyclin $E$ was found in peritumoral tissues compared to cancer-free kidneys, suggesting that cancer cells might secrete factors having a profound influence on the metabolism of neighbouring tissues. A significant, positive correlations between E2F1 protein and total cyclin E mRNA, as well as between E2F1 protein and full length cyclin E protein were found in cancer-free kidneys and in peritumoral tissues, but not in ccRCCs. The overexpression of cyclin E positively correlated with the decreasing degree of tumor differentiation, implicating a role for cyclin $\mathrm{E}$ in the promotion of tumorigenesis.
\end{abstract}

Keywords: human clear cell renal cell carcinoma (ccRCC), gene for cyclin E (CCNE), E2F1 transcription factor, cyclin E, low molecular weight forms of cyclin E (LMW)

\section{INTRODUCTION}

Oncogenesis results from deregulation of the cell cycle and alteration of apoptosis (Evan et al., 2001). The " $R$ " restriction checkpoint located between $G_{1}$ and $S$ phase of the cell cycle, is controlled by retinoblastoma protein ( $\mathrm{pRB})$. $\mathrm{pRB}$ is not phosphorylated until early $G_{1}$ and in this form it binds and inhibits certain E2F proteins. Its sequential phosphorylation by cyclin D-dependent cdk4/cdk6 kinases and by cyclin E-dependent cdk2 kinase results in its dissociation from the E2F-pRB complex, and the release of E2F1, 2 and 3 activatory members of the E2F transcription factor family (Weintraub et al., 1995; Moroy \& Geisen, 2004). E2F1, the best described member of the E2F family, then activates a number of genes encoding proteins involved in cell cycle progression, including cyclin E gene (CCNE) (Ohtani et al., 1995; Muller et al., 2001). Overexpression of E2F1, but neither its mutations nor gene amplification, has been found in many different cancers (Tsanotulis \& Gorgoulis, 2005; Fang \& Han, 2006).

The gene for cyclin $\mathrm{E}$, one of the key targets of E2F1, contains six putative E2F binding sites, but only the three located most distantly from the transcription start site seem to be involved in gene activation (Geng et al., 1996). A large complex containing E2F4 (inhibitory member of E2F family), among

$\square$ Corresponding author: Alicja Nauman, Department of Biochemistry and Molecular Biology, Medical Center of Postgraduate Education, Marymoncka 99, 01-813 Warszawa, Poland; tel. (48 22) 569 3813, fax (48 22) 569 3712, e-mail: anauman@cmkp.edu.pl

Abbreviations: CCNE, homo sapiens gene for cyclin E; ccRCC, clear cell renal cell carcinoma; cdk, cyclin-dependent kinase; EMSA, electrophoretic mobility shift assay; HPRT, hypoxanthine phosphoribosyltransferase; LMW, low molecular weight forms of cyclin E; phenylmethylsulfonyl fluoride; PMSF, phenylmethylsulfonyl; pRB, retinoblastoma protein; TR, thyroid hormone nuclear receptor. 
others, represses transcription of this gene until the $\mathrm{G}_{1}$ phase is reached (Polanowska et al., 2001). Once activatory members of the E2F family dissociate from the phosphorylated $\mathrm{pRB}$, they bind to the CCNE promoter, strongly activating its transcription (Ohtani et al., 1995; Geng et al., 1996). CCNE encodes a 395 amino-acid polypeptide, its shorter splice variants, and an isoform containing additional 15 amino acids at the $\mathrm{N}$ terminus (Porter \& Keyomarsi, 2000). The protein accumulates periodically with a maximum at the end of $G_{1}$ phase (Hwang \& Clurman, 2005) and undergoes degradation during the $\mathrm{S}$ phase. The cyclin E-cdk2 complex phosphorylates pRB and interacts with a number of other proteins playing a role not only in the promotion of the cell cycle transition, but also in DNA replication (Jackson et al., 1995) and in apoptosis (Mazumder et al., 2004).

Deregulated cyclin E expression is very common in different cancers (Donnellan \& Chetty, 1999; Schraml et al., 2003; Hwang \& Clurman, 2005). The full length protein, as well as its shorter forms (low molecular weight forms, LMW) that are generated by cyclin E N-terminal proteolysis, accumulate (Porter et al., 2001; Akli \& Keyomarsi, 2003). It might be a result of gene amplification or its excessive activation, mutation, or a result of increased stability of LMW (Schraml et al., 2003; Akli \& Keyomarsi, 2003). LMW proteins seem to be functionally hyperactive and their presence is associated with acceleration of the cell cycle and genomic instability (Spruck et al., 1999; Porter et al., 2001). Accumulation of cyclin E is associated with more advanced stage of the disease, poorer prognosis and shorter survival rates (MullerTidow et al., 2001; Bales et al., 2005).

In this study we used human clear cell renal cell cancer (ccRCC) (Cohen \& McGovern, 2005) as a model system. A number of factors involved in proliferation control are deregulated in this type of cancer including p21, p27, pRB (Haitel et al., 2001), VHL and NFkB (An \& Rettig, 2005), as well as thyroid hormone receptors (TRs) (Puzianowska-Kuznicka et $a l ., 2000 ; 2006)$. In this paper we show that the correlation between the expression of E2F1 and its target gene encoding cyclin E observed in control tissues is lost in ccRCC. In addition, we show that the expression of cyclin E on both mRNA and protein levels is significantly increased in ccRCCs in comparison to peritumoral tissues and cancer-free kidneys, and this increase correlates with the decreasing degree of tumor differentiation, suggesting a role for this protein in the pathogenesis of ccRCC.

\section{MATERIALS AND METHODS}

Tissues. Tissue samples were obtained with the permission of the Ethical Committee of Hu- man Studies from 34 patients during nephrectomy performed due to kidney cancer. Fragments of the tumors as well as of peritumoral tissues (respective controls) were excised and immediately frozen on dry ice. Tissues were also obtained from cancerfree kidneys, excised due to trauma or ectopic position (15, cancer-free controls). ccRCC was diagnosed upon histological examination using WHO criteria. Tumors were divided into three groups depending on the grade of differentiation: G1 - well differentiated $(n=11), G 2$ - intermediate grade of differentiation $(n=14)$, and G3 - poorly differentiated $(n=9)$.

RNA isolation. Frozen tissue $(100 \mathrm{mg})$ was homogenized in a glass-teflon homogenizer in $1 \mathrm{ml}$ of TRIZOL Reagent (Invitrogen). RNA was isolated according to manufacturer's protocol. The RNA concentration was calculated from spectrophotometry measurements.

Real-time PCR. Synthesis of cDNA was performed with RNA isolated from tumor-respective control tissues. Total RNA $(7.5 \mu \mathrm{g})$ was reverse-transcribed with oligo-dT primer in a total volume of 15 $\mu \mathrm{l}$ using RevertAid ${ }^{\mathrm{TM}} \mathrm{H}$ Minus First Strand cDNA Synthesis Kit (Fermentas). Next, cDNA samples were diluted with sterile, deionized water to a volume of $40 \mu \mathrm{l}$. Each PCR reaction was performed with $1.3 \mu \mathrm{l}$ of cDNA solution (corresponding to $250 \mathrm{ng}$ of total RNA). Real-time PCR was performed using a Chromo4 ${ }^{\mathrm{TM}}$ Four-Color Real-Time Detector (Bio-Rad). The sequences of the primers were as follows: for CCNE 5'-GTGGTGCGACATAGAGAACTG-3' and 5'-CGCTGCTCTGCTTCTTACC-3' (PCR product length $257 \mathrm{bp}$ ); for control gene HPRT 5'-TTTGGATTATACTGCCTGAC-3' and 5'-GGACTAATTATGGACAGGAC-3' (350 bp; HPRT is a housekeeping gene encoding the ubiquitously expressed enzyme that catalyses an early step in the purine salvage pathway). The cycles were as follows: $95^{\circ} \mathrm{C}$ for 15 min, then 38 cycles of $95^{\circ} \mathrm{C}$ for $20 \mathrm{~s}, 59^{\circ} \mathrm{C}$ for 20 $\mathrm{s}, 72^{\circ} \mathrm{C}$ for $20 \mathrm{~s}$. PCR products were detected with SYBR-Green I using the QuantiTect ${ }^{\mathrm{TM}}$ SYBR $^{\circledR}$ Green PCR Kit (Qiagen). Expression level of CCNE was normalized against that of HPRT gene.

Isolation of nuclear proteins. The method used for isolation was previously described by Madej et al. (2003). All buffers were supplemented with pepstatin A $(1 \mu \mathrm{g} / \mathrm{ml})$, aprotinin $(2 \mu \mathrm{g} / \mathrm{ml})$ and PMSF $(0.5 \mathrm{mM})$. The amount of nuclear proteins in the supernatant was measured by Bradford's method. Aliquots $(30 \mu \mathrm{l})$ were stored at $-70^{\circ} \mathrm{C}$.

Western blotting. Nuclear extracts $(40 \mu \mathrm{g})$ were resolved on $10 \%$ polyacrylamide gel and transferred onto a nitrocellulose membrane. The membranes were blocked with $5 \%$ nonfat milk in TBS-T buffer $(20 \mathrm{mM}$ Tris/HCl, pH 7.6, $137 \mathrm{mM} \mathrm{NaCl}, 0.1 \%$ Tween-20), washed twice with TBS-T for $10 \mathrm{~min}$ at room temp., then incubated with rabbit polyclonal 
anti-cyclin E primary antibodies (1:100 in TBS-T, Ab3 corresponding to amino acids 381-395 of human cyclin E; Calbiochem), rabbit polyclonal anti-E2F1 antibody (1:100 in TBS-T; C20, Santa Cruz Biotechnology), and with monoclonal anti- $\beta$-actin antibody (1:5000 in TBS-T; Sigma) for $1 \mathrm{~h}$ at room temp., washed 3 times for $10 \mathrm{~min}$ in TBS-T, then incubated for $1 \mathrm{~h}$ at room temp. with horseradish peroxidase-conjugated anti-rabbit or anti-mouse secondary antibodies (1:10000 in TBS-T; Dako), respectively, and washed again as described above. The specific proteins were visualized with an enhanced-chemiluminescence detection system (Supersignal West Pico chemiluminescent substrate; Pierce) according to a standard procedure. The amount of the specific protein was estimated from the densitometry measurements after normalization against the $\beta$-actin band.

Electrophoretic mobility shift assays. The assays were performed with nuclear extracts isolated from ccRCCs and their respective controls. The probes were identical to CCNE promoter fragments containing E2F binding sites: the first binding site 1-E2F 5'-ACGCGGCTTTTTGCCGCTCCAGCGCCGCTC- $3^{\prime}$, and both the second and the third binding sites 2,3-E2F 5'-GCGCCGCGCGCCAGACTTCTCCCGCGTCCCGC-3' (Geng et al., 1996). The probes were labeled by fill-in reaction with Klenow fragment and $\left[\alpha^{-32} \mathrm{P}\right] \mathrm{dCTP}$. Five micrograms of each nuclear extract were incubated at room temp. for 20 min in $25 \mu \mathrm{l}$ of binding buffer consisting of $20 \mathrm{mM}$ Hepes, $\mathrm{pH} 7.5,40 \mathrm{mM} \mathrm{KCl}, 10 \mathrm{mM} \mathrm{MgCl}, 1 \mathrm{mM}$ EGTA, $0.5 \mathrm{mM}$ dithiothreitol, $0.1 \%$ Nonindet P-40, $10 \%$ glycerol (Cobrinik et al., 1993) supplemented with $250 \mathrm{ng}-1 \mu \mathrm{g}$ of $\mathrm{dIdC}, 0.5 \mathrm{ng}$ of the probe, and protease inhibitors. If required, the samples were supplemented with 25 -fold molar excess of specific competitor or non-specific competitor 5'-CCTGCTGATCTATCAGCACAGATTAG-3'. The products of the reaction were resolved on a $5 \%$ native gel. Gels were then dried and exposed against Kodak film for $24 \mathrm{~h}$.

Statistical analysis. Data were presented as mean values \pm S.E.M. Statistical analysis was performed using one-way ANOVA, Tukey test, and the nonparametric Spearman correlation test (95\% confidence intervals) with $P<0.05$ considered statistically significant.

\section{RESULTS}

The amount of E2F1 protein in ccRCC and in control tissues

The amounts of E2F1 protein in ccRCCs and in peritumoral tissues were determined by Western blot (Fig. 1A). Overexpression of this protein was seen in $89 \%$ of cancer samples compared to their respective controls (Fig. 1B). In $44.5 \%$ of the cases the amount of E2F1 was higher by more than $50 \%$ of that in the respective control, in $44.5 \%$ of the cases it was up to $50 \%$ higher than that in the respective control, while in the remaining $11 \%$ the amount of E2F1 was lower in cancers than in peritumoral tissues. The difference between the mean amounts of E2F1 in the respective controls pooled together and in G1 cases was not significant $(P=0.4574)$, but it reached significance in G2 and G3 cases $(P=0.00314$ and $P<0.0001$ ) (Fig. 1C).

The binding of E2F proteins to the binding sites from cyclin E promoter

Electrophoretic mobility shift assays of E2F transcription factors binding to CCNE promoter-like sequences were performed under previously established conditions (Cobrinik et al., 1993; Geng et al., 1996). It has previously been shown that the first three out of the six putative E2F binding sites in human CCNE promoter are involved in the regulation of CCNE activity (Geng et al., 1996). Therefore, the probes used by us were identical to the first (1-E2F), or the second and the third (2,3-E2F) E2F binding sites. The band pattern we observed was identical to the one described before by other authors. The full set of EMSA performed with both E2F probes and nuclear extracts from ccRCC-respective control pairs revealed that the binding was slightly more efficient in $44.5 \%$, equal in $33.3 \%$, and weaker in $22.2 \%$ of cancer cases compared to the respective controls as shown by densitometric measurements of the specific bands (Fig. 1D). It should be noted that the majority of the ccRCC cases with unchanged or lower protein binding to the E2F recognition sites from CCNE promoter were characterized by E2F1 overexpression. This suggests that in cCRCC tissues other factors might be present that either sequester E2F1 or interfere with its binding to the probe.

The amount of cyclin E mRNA in ccRCCs, in peritumoral tissues, and in cancer-free kidneys

The amount of the specific cyclin E mRNA was checked by means of a real-time PCR (Fig. 2). In all cases the amount of mRNA was higher in ccRCC than in the respective control. The mean amount of cyclin E mRNA in G1, G2, and G3 cases was significantly higher than the mean amount of this mRNA in their respective controls $\mathrm{C} 1, \mathrm{C} 2$, and $\mathrm{C} 3$ $(P=0.03687, P=0.00071, P=0.0028$, respectively). Similarly, the mean amount of cyclin E mRNA in G1, G2 and G3 cases was significantly higher than in cancerfree kidneys $(P=0.00588, P<0.0001$ and $P=0.00286$, respectively). It is noteworthy that in comparison to 
A

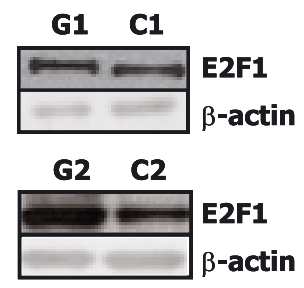

G3 C3

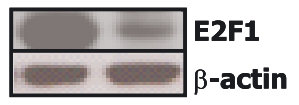

C

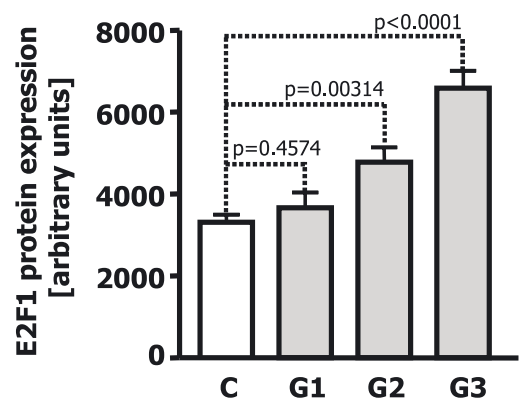

B

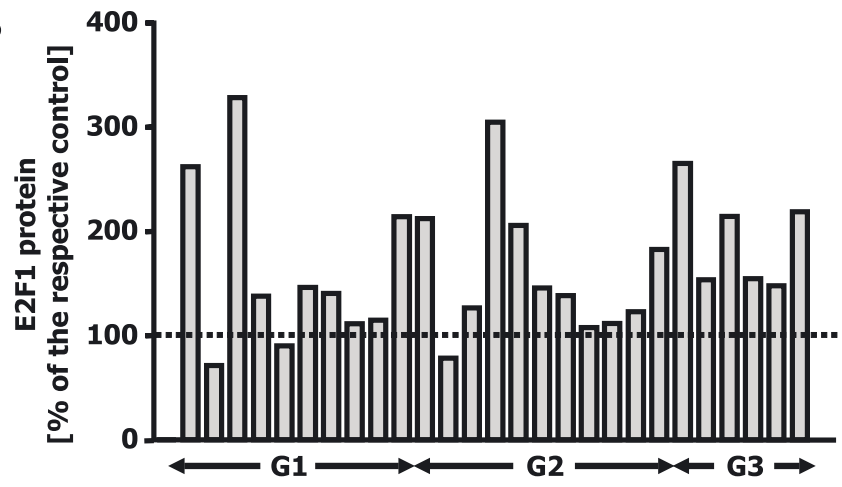

D

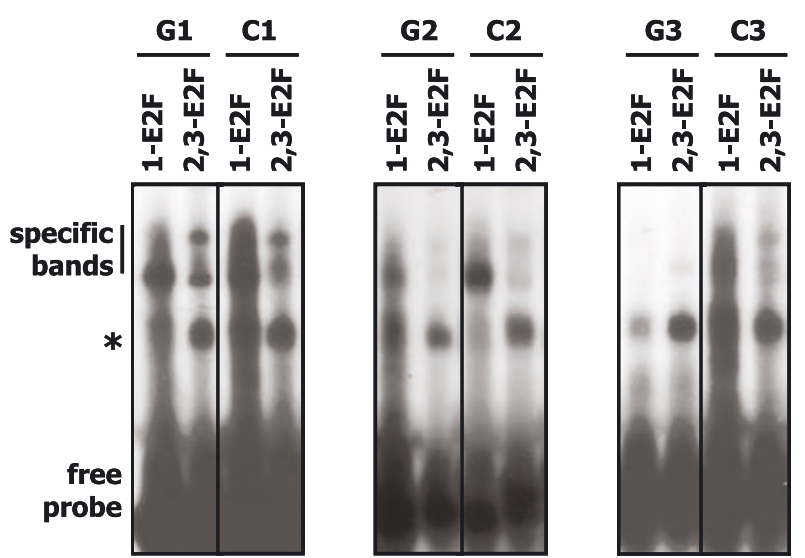

Figure 1. Amount of E2F1 protein in representative ccRCCs and in their respective controls, and the binding of E2Fs to $C C N E$ promoter.

A. Representative immunoblots of nuclear extracts isolated from ccRCCs and their respective controls, probed with antiE2F1 antibody. The membranes were re-probed with anti- $\beta$-actin antibody. B. The amount of E2F1 protein in ccRCCs as percentage of its amount in the respective controls. C. The mean amounts of E2F1 protein in ccRCCs and in the respective controls pooled together. D. Electrophoretic mobility shift assay of the same ccRCC-respective control nuclear extract pairs performed with the probes resembling functionally active E2F binding sites from CCNE promoter. 1-E2F: first E2F binding site; 2,3-E2F: third binding sites. G1, G2, G3: grades of ccRCC differentiation; C: respective controls pooled together; C1, C2, C3: controls for G1, G2, G3, respectively; *non-specific binding.

the mean amount of cyclin E mRNA in cancer-free kidneys, the mean amount of this mRNA in $\mathrm{C} 1$ and C 2 controls was significantly higher $(P=0.02509$ and 0.00233 , respectively). The difference between cancer-free controls and C3 controls was not significant.

Correlations between E2F1 protein and cyclin E mRNA

A significant positive correlation between E2F1 protein and total cyclin E mRNA was found in cancer-free kidneys $(\mathrm{r}=0.8652, \quad P=0.0003)$ (Fig. $3 \mathrm{~A})$ and in peritumoral control tissues $(\mathrm{r}=0.5390$, $P=0.0096)$ (Fig. 3B), but not in clear cell renal cell carcinomas $(\mathrm{r}=0.1346, P=0.5212)$ (Fig. $3 C)$.

The expression of total cyclin E protein and its low molecular weight forms

Total amounts of cyclin E and of LMW were evaluated in human ccRCC-respective control pairs and in cancer-free controls. Blots were probed with antibodies generated against a synthetic peptide corresponding to amino acids 381-395 of human cyclin $E$ that detect full length protein and smaller proteins corresponding to different forms of cyclin E. Bands of 52 and $51 \mathrm{kDa}$ representing large forms of cyclin E, as well as predominant 42,36 , and $30 \mathrm{kDa}$ bands representing LMW forms of cyclin E were detected in ccRCC tissues. In addition to the full length forms, two bands, 42 and $36 \mathrm{kDa}$, were observed in cancer-free controls, while the 42,36 , and in some cases - $30 \mathrm{kDa}$ LMW forms were present in tumorsurrounding tissues (Fig. 4A). Densitometric analysis showed that the mean total cyclin E content in cancer-free tissues expressed in arbitrary units was $3717 \pm 274$, and in peritumoral controls the value was $4685 \pm 226$. It is noteworthy that this difference was significant $(P=0.02326)$. The difference between the total cyclin $\mathrm{E}$ amount in cancer-free controls and $\mathrm{C} 1$ controls $(3878 \pm 464)$ was not significant $(P=0.77569)$, but it was highly significant for C2 $(4897 \pm 289)$ and 


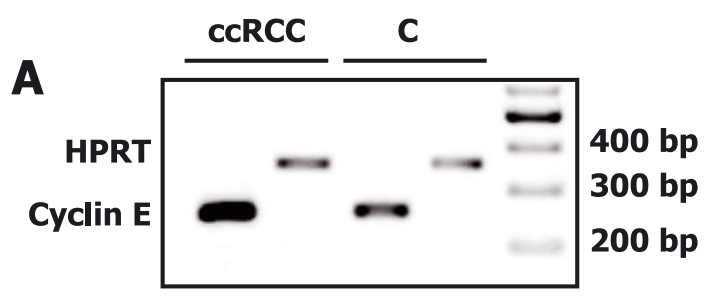

B

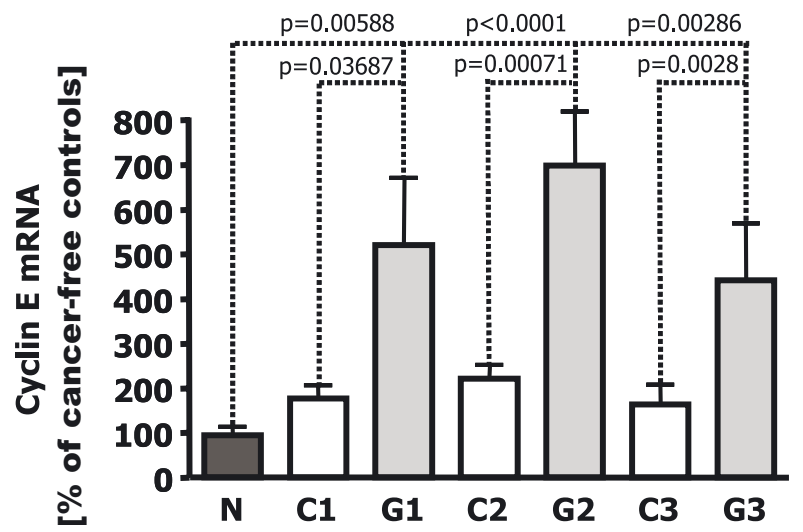

Figure 2. Amount of cyclin E mRNA in ccRCCs, in their respective controls, and in cancer-free kidneys.

cDNA used in classic PCR and in real-time PCR reactions was made on the template of total RNA isolated from ccRCCs and from their respective controls. A. Ethidium bromide staining of real-time PCR-amplified CCNE product and HPRT control gene product (28 cycles). B. The mean amount of cyclin E mRNA in ccRCCs and in their respective controls as percentage of the mean amount of this mRNA in cancer-free kidneys. N: cancer-free controls; G1, G2, G3: grades of ccRCC differentiation; C1, C2, C3: controls for G1, G2, G3, respectively.

C3 $(5115 \pm 408)$ controls $(P=0.00735$ and $P=0.0084$, respectively). The mean amount of cyclin E in G1 tumors was $5514 \pm 407$, in G2 $6183 \pm 510$, and in G3 $10122 \pm 1627$. The differences between cancer-free controls and G1, G2, and G3 tumors were significant $(P=0.00122, \quad P=0.00047$, and 0.00026 , respectively), as were the differences between C1 and G1, C2 and G2, as well as C3 and G3 $(P=0.01748, P=0.04123$, and $P=0.00605$, respectively) (Fig. 4B).

Analysis of LMW forms of cyclin E showed that their mean amount in cancer-free controls was $1305 \pm 337$, in C1 controls it was $1448 \pm 286$, in C2 $1725 \pm 281$, and in C3 $2072 \pm 468$. The differences between cancer-free controls and C1, C2, C3 were not significant $(P=0.77055, P=0.36174, P=0.23256$, respectively). The differences between cancer-free controls and G1 $(2768 \pm 352)$, G2 $(3788 \pm 603)$, and G3 $(4480 \pm 896)$ tumors were significant $(P=0.00843$, $P=0.00081$, and $P=0.00062$, respectively). The differences between C1 and G2, C2 and G2, as well as C3
A

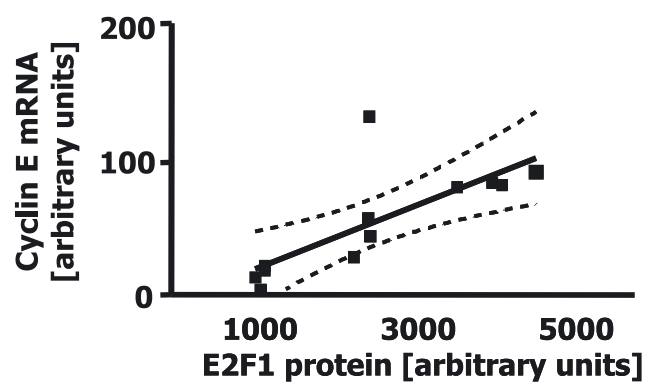

B

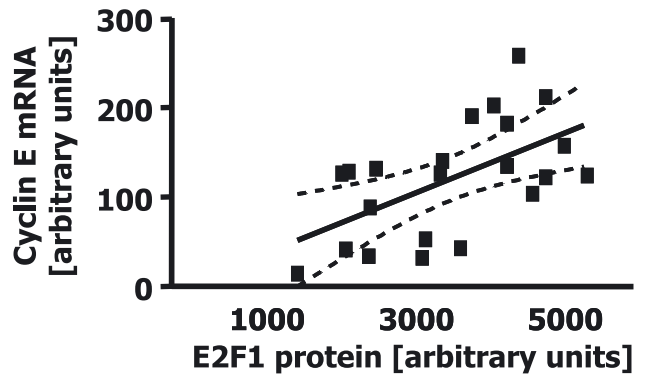

C

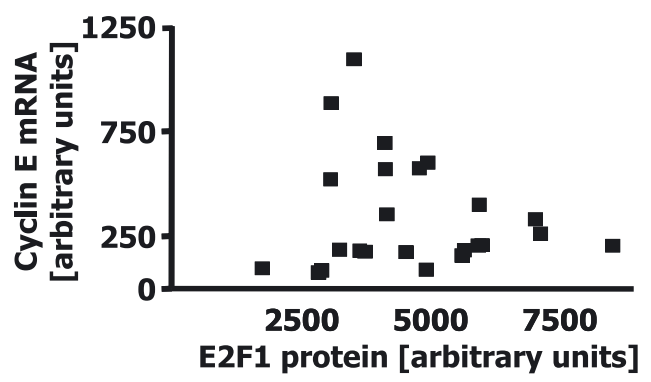

Figure 3. Correlation between E2F1 protein and cyclin E mRNA amounts in ccRCCs, in their respective controls, and in cancer-free kidneys.

A. A significant positive correlation between E2F1 protein and cyclin E mRNA levels in cancer-free kidneys $(\mathrm{r}=0.8652, P=0.0003)$. B. A significant positive correlation between E2F1 protein and cyclin E mRNA levels in peritumoral tissues $(\mathrm{r}=0.5390, P=0.0096)$. C. Lack of such correlation in ccRCCs $(\mathrm{r}=0.1346, P=0.5212)$.

and G3 were also significant $(P=0.00931, P=0.00491$, $P=0.0017$, respectively) (Fig. $4 \mathrm{C}$ ). In cancer-free tissues the LMW forms constituted $24.33 \pm 4.92 \%$ of total cyclin E, in the respective controls pooled together they represented $31 \pm 2.95 \%$, while in G1 tumors $56.67 \pm 4.50 \%$, in G2 $52.56 \pm 6.21 \%$, and in G3 $50.31 \pm 3.07 \%$. These differences were statistically significant (cancer-free controls vs. G1, G2, and G3: $P<0.0001, P=0.00183$, and 0.00018 , respectively; the respective controls vs. G1, G2, and G3: $P<0.0001$, $P=0.00208$, and 0.00047 , respectively).

Correlations between E2F1 protein and cyclin E protein

On the basis of the available data, it is justified to presume that the amount of full length cyclin 
A
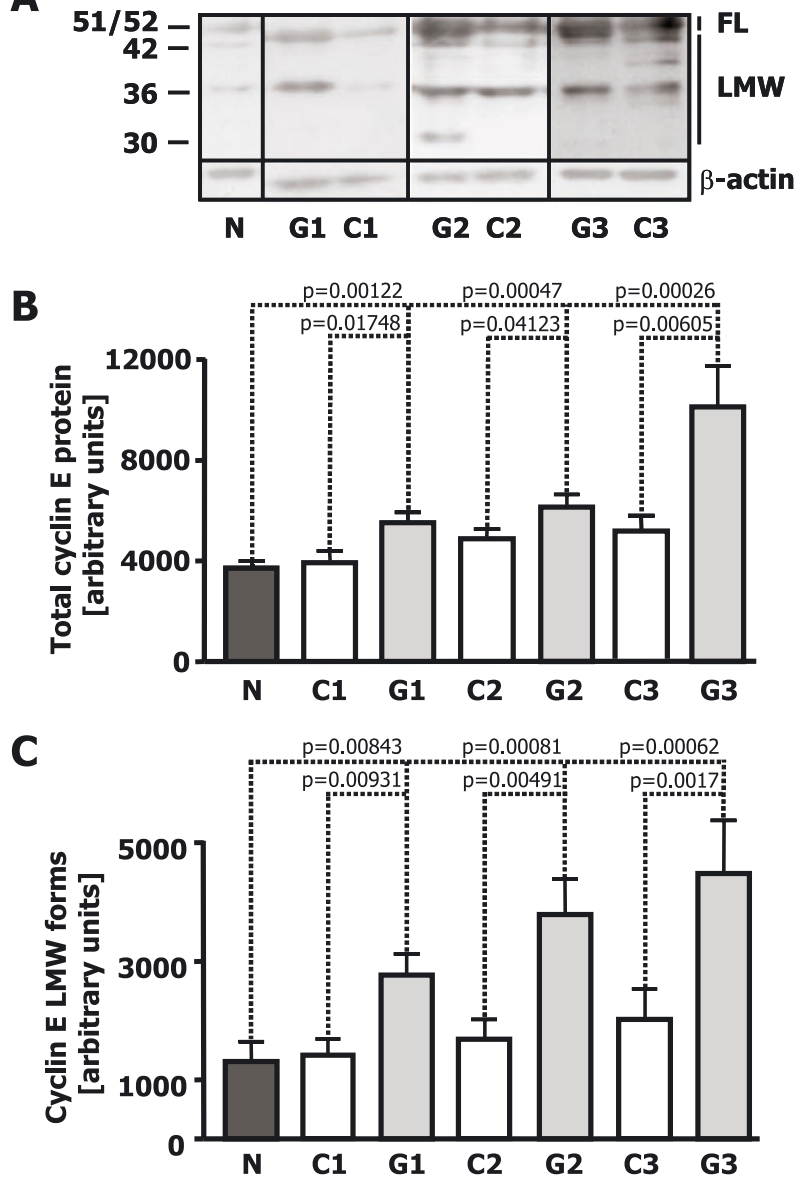

Figure 4. Amount of total cyclin E and its low molecular weight forms in ccRCCs, in their respective controls, and in cancer-free kidneys.

A. Typical expression of full length cyclin E $(52,51 \mathrm{kDa})$ and its LMW forms $(42,36,30 \mathrm{kDa})$ as analyzed by immunoblotting. FL: full length; LMW: low molecular weight forms. B. Mean total cyclin E expression in cancer-free, peritumoral control, and cancer tissues. C. Expression of LMW forms of cyclin E in cancer-free, peritumoral control, and cancer tissues. N: cancer-free kidneys; G1, G2, G3: grades of ccRCC differentiation; C1, C2, C3: controls for G1, G2, G3, respectively.

E protein corresponds to the transcriptional activity of CCNE gene. Therefore, the correlation between E2F1 protein and full length cyclin E was analyzed. Such correlation was significant in cancer-free kidneys $(\mathrm{r}=0.5919, P=0.0426)$ (Fig. $5 \mathrm{~A})$ and in peritumoral tissues $(\mathrm{r}=0.4708, P=0.0152)$ (Fig. $5 \mathrm{~B})$, but not in ccRCCs $(\mathrm{r}=0.1887, P=0.3772)$ (Fig. 5C).

Correlations between cyclin E mRNA and different forms of cyclin E protein

A significant positive correlation between total cyclin E mRNA and the full length protein forms was found in cancer-free kidneys $(r=0.6294$, $P=0.0283$ ) (Fig. 6A) and in peritumoral tissues
A

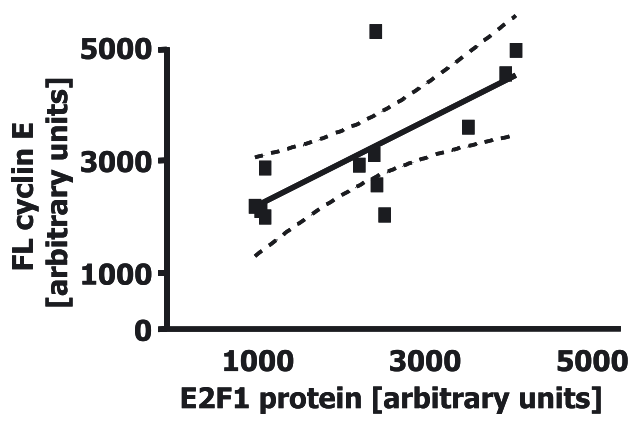

B
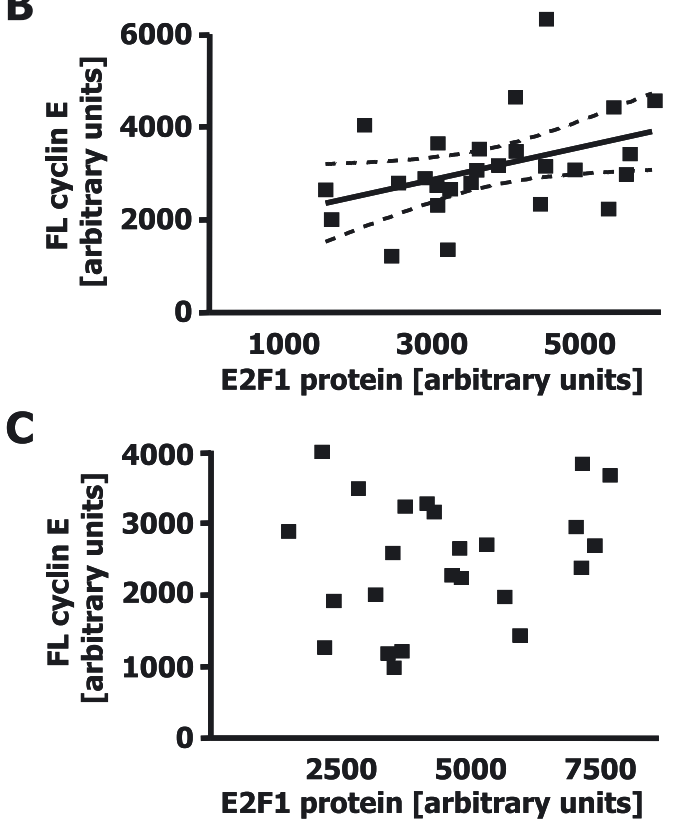

Figure 5. Correlation between E2F1 protein and full length cyclin E protein amounts in ccRCCs, in their respective controls, and in cancer-free kidneys.

A. A significant positive correlation between E2F1 protein and full length cyclin $\mathrm{E}$ protein amounts in cancer-free kidneys $(\mathrm{r}=0.5919, P=0.0426)$. B. A significant correlation in peritumoral tissues $(\mathrm{r}=0.4708, P=0.0152)$. C. Lack of such correlation in ccRCCs $(\mathrm{r}=0.1887, P=0.3772)$.

$(\mathrm{r}=0.5851, P=0.0107)$ (Fig. 6B), but not in ccRCCs $(\mathrm{r}=0.3353, P=0.1484)$ (Fig. 6C). There was a significant correlation between the amount of total cyclin E mRNA and the amount of total (full length and LMW) cyclin E proteins in cancer-free kidneys $(\mathrm{r}=0.6853, P=0.0139)$, but not in peritumoral tissues or in cancer tissues. There was no correlation between the amount of total cyclin E mRNA and the amount of cyclin E LMW forms in any type of tissues analyzed.

A significant positive correlation between total cyclin $\mathrm{E}$ and full length cyclin $\mathrm{E}$ was found in cancer-free kidneys $(\mathrm{r}=0.8571, P<0.0001)$, in peritumoral tissues $(\mathrm{r}=0.7684, P<0.0001)$, and in ccRCCs $(\mathrm{r}=0.6093, P=0.0007)$. The correlation between total cyclin E and LMW forms was also significant in all tissue types analyzed $(r=0.5783, P=0.0239$ in cancerfree kidneys, $r=0.8734, P<0.0001$ in the respective 
A

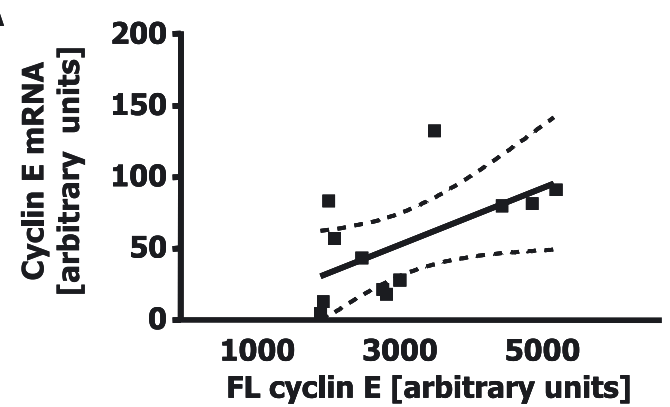

B

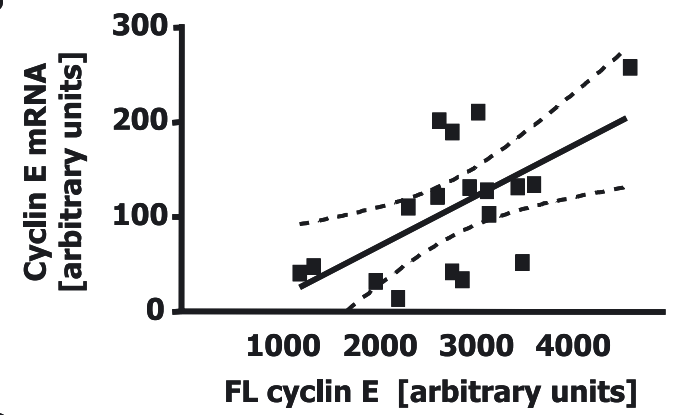

C

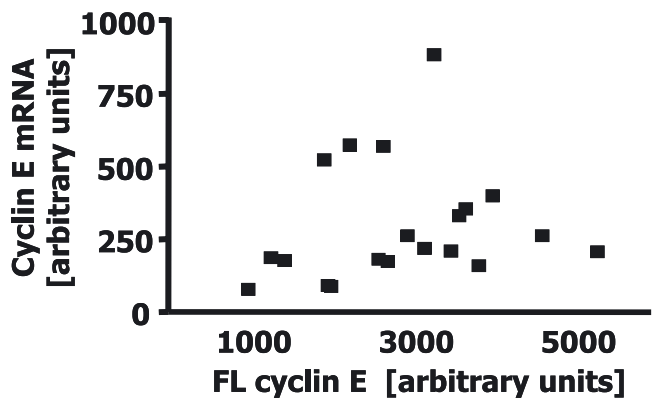

Figure 6. Correlation between cyclin E mRNA and full length protein amounts in ccRCCs, in their respective controls, and in cancer-free kidneys.

A. A significant positive correlation between cyclin E mRNA and full length cyclin E protein amounts in cancerfree kidneys $(\mathrm{r}=0.6294, P=0.0283)$. B. A significant correlation in the respective control tissues $(\mathrm{r}=0.5851, P=0.0107)$. C. Lack of such correlation in ccRCCs $(r=0.3353$, $P=0.1484)$.

controls, $\mathrm{r}=0.8480, P<0.0001$ in ccRCCs). A statistically significant correlation between the amount of full length cyclin $\mathrm{E}$ and the amount of LMW forms was found in cancer-free kidneys $(r=0.8303$, $P=0.0047)$. However, once cancer-free cases without LMW forms detected were added to this analysis, the correlation became non-significant $(\mathrm{r}=0.1928$, $P=0.4913$ ). Such a correlation was significant in the respective controls $(\mathrm{r}=0.4429, P=0.039)$, but not in ccRCC tissues $(\mathrm{r}=0.1374, P=0.4945)$.

\section{DISCUSSION}

Two major mechanisms might lead to cyclin E overexpression in tumors: abnormally high transcription rate, and slower protein degradation. In this work we examined the pathway which potentially increases cyclin E abundance as a result of the undue activation of its gene by an excess of E2F1 transcription factor. We found a significant positive correlation between E2F1 protein and total cyclin E mRNA levels in cancer-free kidneys and in peritumoral tissues, but not in ccRCCs. Furthermore, there was no correlation in the cancers between CCNE promoter binding by E2F factors and the level of cyclin E mRNA. At least two mechanisms come to mind to explain these results. First, the increase in the amount of E2F1 protein might not translate into its increased transcriptional activity. Indeed, such activity of E2F1 depends not only on the level of this protein, but also on the amount and function of other proteins: pRB, whose activity is significantly disturbed in the majority of tumors, other members of the E2F family that compete with E2F1 for binding to DNA, or altered function of other proteins. Second, factors other than E2F1 could be also involved in direct regulation of $C C N E$ promoter in cCRCC. It is noteworthy that our data are consistent with the results obtained by Pajalunga and Crescenzi (2004) who showed that forced overexpression of E2F factors did not increase CCNE transcription, but specifically stabilized cyclin $\mathrm{E}$ by reducing its conjugation with ubiquitin and, consequently, its degradation.

In cancer tissues, there was no correlation between the amount of total cyclin E mRNA and the amount of total cyclin E or LMW forms of this protein that are products of proteolysis of full length cyclin E. This was an expected result since it has previously been shown that the increase in the amount of cyclin E in cancers is dependent not only on the increase of gene transcription, but also on the presence and accumulation of LMW forms that are both more stable and more active than the full length protein (Porter et al., 2001; Akli \& Keyomarsi, 2003; Pajalunga \& Crescenzi, 2004; Bedrosian et al., 2004). However, we observed a lack of such correlations also in peritumoral tissues. It is possible that cancer cells secrete factors having a profound influence on the metabolism of the adjacent tissues, and that the LMW cyclin E forms observed in the respective controls arise not only as a result of the increased transcription of CCNE, but also due to proteolysis of full length protein (as in the cancer cells themselves) as suggested by the finding that in these tissues the amount of LMW forms correlated with the amount of full length cyclin E.

Taken together, our data show that the expression of cyclin E and its LMW forms was excessive in ccRCC tissues both in well differentiat- 
ed and in poorly differentiated cases. This overexpression correlated with the decreasing degree of tumor differentiation suggesting a role for cyclin $\mathrm{E}$ both in the initiation, and in the promotion of kidney tumorigenesis.

\section{Acknowledgements}

This work was supported by the Polish State Committee for Scientific Research grants 2 P05A 128 26 (to AN) and 3 P04A 01225 (to MPK).

\section{REFERENCES}

Akli S, Keyomarsi K (2003) Cyclin E and its low molecular weight forms in human cancer and as targets for cancer therapy. Cancer Biol Ther 2: S38-S47.

An J, Rettig MB (2005) Mechanism of von Hippel-Lindau protein-mediated suppression of nuclear factor kappa B activity. Mol Cell Biol 25: 7546-7556.

Bales E, Mills L, Milam N, McGahren-Murray M, Bandyopadhyay D, Chen D, Reed JA, Timchenko N, van den Oord JJ, Bar-Eli M, Keyomarsi K, Medrano EE (2005) The low molecular weight cyclin $\mathrm{E}$ isoforms augment angiogenesis and metastasis of human melanoma cells in vivo. Cancer Res 65: 692-697.

Bedrosian I, Lu KH, Verschraegen C, Keyomarsi K (2004) Cyclin E deregulation alters the biologic properties of ovarian cancer cells. Oncogene 23: 2648-2657.

Cobrinik D, Whyte P, Peeper DS, Jacks T, Weinberg RA (1993) Cell cycle-specific association of E2F with the p130 E1A-binding protein. Genes Dev 7: 2392-2404.

Cohen HT, McGovern FJ (2005) Renal cell carcinoma. $N$ Engl J Med 353: 2477-2490.

Donnellan R, Chetty R (1999) Cyclin E in human cancers. FASEB J 13: 773-780.

Evan GI, Vousden KH (2001) Proliferation, cell cycle and apoptosis in cancer. Nature 411: 342-348.

Fang ZH, Han ZC (2006) The transcription factor E2F: a crucial switch in the control of homeostasis and tumorigenesis. Histol Histopathol 21: 403-413.

Geng Y, Eaton EN, Picon M, Roberts JM, Lundberg AS, Gifford A, Sardet C, Weinberg RA (1996) Regulation of cyclin E transcription by E2Fs and retinoblastoma protein. Oncogene 12: 1173-1180.

Haitel A, Wiener HG, Neudert B, Marberger M, Susani M (2001) Expression of the cell cycle proteins p21, p27, and $\mathrm{pRb}$ in clear cell renal cell carcinoma and their prognostic significance. Urology 58: 477-481.

Hwang HC, Clurman BE (2005) Cyclin E in normal and neoplastic cell cycles. Oncogene 24: 2776-2786.

Jackson PK, Chevalier S, Philippe M, Kirschner MW (1995) Early events in DNA replication require cyclin $\mathrm{E}$ and are blocked by p21CIP1. J Cell Biol 130: 755-769.

Kamiya Y, Puzianowska-Kuznicka M, McPhie P, Nauman J, Cheng SY, Nauman A (2002) Expression of mutant thyroid hormone nuclear receptors is associated with human renal clear cell carcinoma. Carcinogenesis 23: 25-33.
Madej A, Puzianowska-Kuznicka M, Tanski Z, Nauman J, Nauman A (2003) Witamin D receptor binding to DNA is altered without the change in its expression in human renal clear cell cancer. Nephron Exp Nephrol 93e: e150-e157.

Mazumder S, DuPree EL, Almasan A (2004) A dual role of cyclin $\mathrm{E}$ in cell proliferation and apoptosis may provide a target for cancer therapy. Curr Cancer Drug Targets 4: 65-75.

Moroy T, Geisen C (2004) Cyclin E. Int J Biochem Cell Biol 36: 1424-1439.

Muller H, Bracken AP, Vernell R, Moroni MC, Christians F, Grassilli E, Prosperini E, Vigo E, Oliner JD, Helin K (2001) E2Fs regulate the expression of genes involved in differentiation, development, proliferation, and apoptosis. Genes Dev 15: 267-285.

Muller-Tidow C, Metzger R, Kugler K, Diederichs S, Idos G, Thomas M, Dockhorn-Dworniczak B, Schneider PM, Koeffler HP, Berdel WE, Serve H (2001) Cyclin E is the only cyclin-dependent kinase 2-associated cyclin that predicts metastasis and survival in early stage nonsmall cell lung cancer. Cancer Res 61: 647-653.

Ohtani K, DeGregori J, Nevins JR (1995) Regulation of the cyclin E gene by transcription factor E2F1. Proc Natl Acad Sci USA 92: 12146-12150.

Pajalunga D, Crescenzi M (2004) Regulation of cyclin E protein levels through E2F-mediated inhibition of degradation. Cell Cycle 3: 1572-1578.

Polanowska J, Fabbrizio E, Le Cam L, Trouche D, Emiliani S, Herrera R, Sardet C (2001) The periodic down regulation of cyclin $\mathrm{E}$ gene expression from exit of mitosis to end of $G_{1}$ is controlled by a deacetylase- and E2Fassociated bipartite repressor element. Oncogene 20: $4115-4127$.

Porter DC, Keyomarsi K (2000) Novel splice variants of cyclin E with altered substrate specificity. Nucleic Acids Res 28: E101

Porter DC, Zhang N, DanesC, McGahren MJ, Harwell RM, Faruki S, Keyomarsi K (2001) Tumor specific proteolytic processing of cyclin E generates hyperactive lowermolecular-weight forms. Mol Cell Biol 21: 6254-6269.

Puzianowska-Kuznicka M, Nauman A, Madej A, Tanski Z, Cheng S, Nauman J (2000) Expression of thyroid hormone receptors is disturbed in human renal clear cell carcinoma. Cancer Lett 155: 145-152.

Puzianowska-Kuznicka M, Pietrzak M, Turowska O, Nauman A (2006) Thyroid hormones and their receptors in the regulation of cell proliferation. Acta Biochim Polon 53: 641-650.

Schraml P, Bucher C, Bissig H, Nocito A, Haas P, Wilber K, Seelig S, Kononen J, Mihatsch MJ, Dirnhofer S, Sauter G (2003) Cyclin E overexpression and amplification in human tumours. J Pathol 200: 375-382.

Spruck CH, Won KA, Reed SI (1999) Deregulated cyclin E induces chromosome instability. Nature 401: 297-300.

Tsantoulis PK, Gorgoulis VG (2005) Involvement of E2F transcription factor family in cancer. Eur J Cancer 41: 2403-2414.

Weintraub SJ, Chow KNB, Luo RX, Zhang SH, He S, Dean DC (1995) Mechanism of active transcriptional repression by the retinoblastoma protein. Nature 375: 812 815. 